\title{
PATRIMONIALIZAÇÃO DOS ESPAÇOS RELIGIOSOS AFRO-BRASILEIROS: discussões a partir das teorias da sociedade e da cultura ${ }^{12}$
}

\author{
PATRIMONIALIZACIÓN DE LOS ESPACIOS RELIGIOSOS AFRO- \\ BRASILEÑOS: debates basados en teorías de la sociedad y la cultura
}

\author{
PATRIMONIALIZATION OF AFRO-BRAZILIAN RELIGIOUS SPACES: \\ discussions based on theories of society and culture
}

\author{
Walkyria Chagas da Silva Santos ${ }^{3}$
}

\begin{abstract}
Resumo
O presente texto visa apresentar discussões que entrelaçam o tema patrimonialização dos espaços religiosos afrobrasileiros no Estado da Bahia e teorias da sociedade e da cultura. O autor selecionado como central para elaboração do diálogo é Stuart Hall. Stuart, que no livro "Da diáspora: identidades e mediações culturais" apresenta discussões que são interessantes para abordagem da temática, tais como tradição, diáspora e identidade. Para situar o debate, vale informar que, as políticas culturais são iniciadas no Brasil na década de 30 do século XX, e apenas em 1986 é tombado definitivamente o primeiro monumento negro, o Ilê Axé Iyá Nassô Oká. A intenção não é abordar todas as discussões e todos os conceitos trazidos pelo autor, mas sim utilizá-los como ponto de partida para pensar a diáspora e sua relação com os espaços religiosos afro-brasileiros, a relação que se estabelece entre o órgão estatal responsável pela patrimonialização de bens culturais e o povo de santo, e o jogo de poder que se estabelece nessa relação.
\end{abstract}

Palavras-Chave: Patrimonialização de terreiros; teorias da sociedade e da cultura; diáspora.

\section{Resumen}

Este texto tiene como objetivo presentar discusiones que entrelazan el tema patrimonial de los espacios religiosos afrobrasileños en el Estado de Bahía y las teorías de la sociedad y la cultura. El autor seleccionado como central para la elaboración del diálogo es Stuart Hall. Stuart, quien en el libro "De la diáspora: identidades y mediaciones culturales" presenta discusiones que son interesantes para abordar el tema, como la tradición, la

\footnotetext{
${ }^{1}$ Artigo apresentado durante o I Congresso Internacional Online de Estudos sobre Culturas - \#Culturas, realizado de forma online, em outubro de 2019.

${ }^{2}$ As discussões fazem parte da tese que será apresentada ao Programa de Pós-Graduação em Estado e Sociedade da Universidade Federal do Sul da Bahia. A pesquisa é financiada pela Coordenação de Aperfeiçoamento de Pessoal de Nível Superior (CAPES).

${ }^{3}$ Mestra em Políticas Públicas e Segurança Social (UFRB), Doutoranda do Programa de Pós-Graduação em Estado e Sociedade, Do Centro de Formação em Ciências Humanas e Sociais da Universidade Federal do Sul da Bahia (UFSB); Porto Seguro, Bahia, Brasil; Doutoranda em Direito, Faculdade de Direito da Universidade de Brasília (UnB); Brasília, Distrito Federal, Brasil; kyriachagas@yahoo.com.br
} 
diáspora y la identidad. Para situar el debate, vale la pena mencionar que las políticas culturales comenzaron en Brasil en la década de 1930 del siglo XX, y fue solo en 1986 que el primer monumento negro, Ilê Axé Iyá Nassô Oká, se incluyó definitivamente. La intención no es abordar todas las discusiones y todos los conceptos aportados por el autor, sino utilizarlos como punto de partida para pensar sobre la diáspora y su relación con los espacios religiosos afrobrasileños, la relación que se establece entre la agencia estatal responsable. para la patrimonialización de los bienes culturales y la gente de los santos, y el juego de poder que se establece en esta relación.

Palabras claves: Patrimonio de los terreiros; teorías de la sociedad y la cultura; diáspora

\begin{abstract}
This text aims to present discussions that intertwine the heritage theme of Afro-Brazilian religious spaces in the State of Bahia and theories of society and culture. The author selected as central for the elaboration of the dialogue is Stuart Hall. Stuart, who in the book "From the Diaspora: identities and cultural mediations" presents discussions that are interesting to approach the theme, such as tradition, diaspora and identity. In order to situate the debate, it is worth mentioning that cultural policies started in Brazil in the 1930s of the 20th century, and it was only in 1986 that the first black monument, Ilê Axé Iyá Nassô Oká, was definitively listed. The intention is not to address all the discussions and all the concepts brought by the author, but to use them as a starting point to think about the diaspora and its relationship with Afro-Brazilian religious spaces, the relationship that is established between the responsible state agency for the patrimonialization of cultural goods and the people of saints, and the power game that is established in this relationship.
\end{abstract}

Keywords: Patrimonialization of terreiros; theories of society and culture; diaspora.

\title{
INTRODUÇÃO
}

O presente artigo visa apresentar discussões que entrelaçam o tema de pesquisa "Patrimonialização dos espaços religiosos afro-brasileiros: uma análise sobre os terreiros do Estado da Bahia" e a bibliografia abordada no componente "Teorias da sociedade e da cultura" do Programa de Pós-Graduação em Estado e Sociedade da Universidade Federal do Sul da Bahia.

Stuart no livro "Da diáspora: identidades e mediações culturais" apresenta discussões que são interessantes para abordagem da temática de pesquisa, tais como tradição, diáspora e identidade. A intenção não é abordar todas as discussões e todos os conceitos trazidos pelo autor, mas sim utilizá-los como ponto de partida para pensar a diáspora e sua relação com os espaços religiosos afro-brasileiros, a relação que se estabelece entre o órgão estatal responsável pela patrimonialização de bens culturais e o povo de santo, e o jogo de poder que se estabelece nessa relação.

Vale informar que, as políticas culturais são iniciadas no Brasil na década de 30 do século XX, contudo, até a década de 80 apenas os monumentos que representavam o denominado patrimônio de "pedra e cal" (FONSECA, 2009) foram tombados pelo Estado brasileiro. A denominação deriva do fato do Instituto do Patrimônio Histórico e Artístico 
Nacional (IPHAN) voltar o seu olhar essencialmente para o patrimônio material, em estilo barroco, que rememora o período colonial e imperial da história do Brasil, mas rememora uma história bem marcada, a história dos colonizadores/invasores.

Assim, os bens culturais de indígenas, negros e demais povos que participaram do processo de formação da sociedade brasileira foram excluídos ${ }^{4}$ do âmbito de proteção. Apenas em 1986 é tombado definitivamente o primeiro monumento negro, o Ilê Axé Iyá Nassô Oká (Terreiro da Casa Branca), no município de Salvador. Portanto, a patrimonialização é utilizada para reconhecer os bens da cultura hegemônica e em poucos casos ela também reconhece o patrimônio subalterno.

Ao realizar a análise da patrimonialização dos espaços religiosos afro-brasileiros, algumas discussões apresentadas pelos estudos culturais são muito importantes, eis o grande motivo para Stuart Hall ser o centro das atenções aqui. Portanto, a seguir serão apresentados algumas reflexões concernentes a este contexto.

\section{PATRIMONIALIZAÇÃO DOS ESPAÇOS RELIGIOSOS AFRO-BRASILEIROS: DIÁLOGO COM AS TEORIAS DA SOCIEDADE E DA CULTURA}

Ao escrever sobre sujeitos que representam um grupo minoritário, muitas vezes, ocorre dentro da academia o questionamento quanto à cientificidade ou não da pesquisa, se a pesquisa é uma pesquisa cientifica ou militância. Muitos defendem que é possível fazer as duas coisas, a postura no mundo acadêmico não deve ficar afastada da postura diante da vida. Assim, ao ler Stuart Hall o "mundo sorriu novamente". Com suas metáforas Hall trouxe algo muito importante, os estudos culturais não podem se afastar da prática, defendê-lo, estar nele é uma postura política. Assim, é função também dos negros e das negras que estão na academia, "fazer um trabalho teórico que contribua para uma ideologia e uma cultura “populares” em contraposição à cultura do bloco de poder” (HALL, 2003).

Esse fazer teórico que se contrapõe as posturas hegemônicas, que questiona, que reconstrói, muitas vezes acaba reservando para o pesquisador um lugar inferiorizado dentro da academia, mas Stuart Hall, Beatriz Nascimento ${ }^{5}$ e tantos outros e outras se definiram como seres diaspóricos justamente para demarcar o seu lugar. Para Beatriz foi mais difícil, afinal ser

\footnotetext{
${ }^{4}$ Ou incluídos de forma incipiente.

${ }^{5}$ Livro: Eu sou Atlântica: sobre a trajetória de vida de Beatriz Nascimento de Alex Ratts.
} 
mulher, negra e periférica tem suas durezas. Mas é importante ressaltar a postura de Hall e a "lição" que ele deixa, "Ao definir-se como intelectual diaspórico Hall escolhe o lugar que o discurso eurocêntrico destina a ele, um lugar de negro". (HALL, 2003).

Ao abordar o mito fundador e a concepção fechada do que significa tribo, diáspora e pátria, Hall fala sobre o problema de pensar a identidade cultural a partir da tradição,

\begin{abstract}
Possuir uma identidade cultural nesse sentido é estar primordialmente em contato com um núcleo imutável e atemporal, ligando ao passado o futuro e o presente numa linha ininterrupta. Esse cordão umbilical é o que chamamos de "tradição", cujo teste é o de sua fidelidade às origens, sua presença consciente diante de si mesma, sua "autenticidade". É, claro, um mito - com todo o potencial real dos nossos mitos dominantes de moldar nossos imaginários, influenciar nossas ações, conferir significado às nossas vidas e dar sentido à nossa história. (HALL, 2003).
\end{abstract}

Assim, Hall alerta que os mitos fundadores são transitórios, fundamentalmente aistóricos e anacrônicos. Portanto, a identidade para os caribenhos em diáspora, e aqui ampliando para os demais povos diaspóricos, inclusive para os afro-brasileiros, identidade e história estão interligadas, posto que, as sociedades são formadas por vários povos de origens diversas, e a relação com o passado, com a história é assentada a partir de lutas, rupturas, genocídios e conquistas. Por conseguinte, mais uma vez é derrubado o mito fundador da nação brasileira assentado sobre o triangulo "brancos, negros e índios", discurso utilizado para hierarquizar os povos, as culturas e as religiões, relegando a clandestinidade as religiões pertencentes às minorias étnicas.

A Constitucional de 1988 garantiu novos direitos e assegurou algumas bandeiras de luta do momento negro, tais como: o inclusão do crime de racismo, o reconhecimento estatal das terras remanescentes de quilombos e do patrimônio cultural de todos os povos que participaram do "processo civilizatório nacional". Apesar dos avanços no texto constitucional, o IPHAN, órgão responsável por realizar os processos que resultam em ações de proteção e preservação dos bens culturais busca a tradição, a pureza, o imutável ao analisar os processos de pedido de tombamento requisitados por espaços religiosos afro-brasileiros. Em suas análises os servidores e conselheiros do Conselho Consultivo do Patrimônio Histórico e Artístico Nacional, em sua maioria, buscam as seguintes características, conforme livro publicado pelo IPHAN, "Políticas de acautelamento do IPHAN para templos de Culto afrobrasileiros": a) terreiros de candomblé antigos e tradicionais; b) terreiros que se constituem como elementos singulares; c) casas matrizes; d) relevância histórica, etnográfica e paisagística. (AMORIM, 2012). 
A postura do IPHAN ao tombar bens culturais que representam essencialmente a religiosidade da nação Ketu não estaria em busca da originalidade, da cópia? Alguns estudos demonstram que o povo da nação Ketu foi aquele que conseguiu preservar suas tradições de maneira mais fidedigna, posto que, foram os últimos a aportar em solo brasileiro. Os da nação Angola ${ }^{6}$ seriam mais sincréticos devido aos séculos de contato com as outras culturas, posto que, chegaram no momento inicial do tráfico de escravizados. Foram os terreiros de candomblé da Nação Ketu os mais estudados pela academia no período de formação do campo estudos sobre os negros/estudos sobre as religiões afro-brasileiras.

Conforme informado inicialmente, apenas da década de 1980 é tombado o primeiro momento negro. Após mais de 30 anos da realização do primeiro tombamento, as mudanças na política cultural voltada para os espaços religiosos afro-brasileiros não são tão expressivas quanto o povo de santo desejava e esperava. Dos onze terreiros tombados, nove estão localizados no Estado da Bahia, um no Estado do Maranhão e um no Estado de Pernambuco, são eles: o Ilê Axé Iyá Nassô Oká (Terreiro da Casa Branca); o Ilê Axé Opô Afonjá; o Ilê iyá Omi Axé Iyamassê (Terreiro do Gantois); o Manso Banduquenqué (Bate Folha); o Ilê Maroiálaji Alakêto; o Ilê Axé Oxumarê; e, o Terreiro Tumba Junsara, todos em Salvador/BA; o Zoogodo Bogum Malê Seja Undé (Terreiro Roça do Ventura), em Cachoeira/BA; o Omo Ilê Agbôula, na Ilha de Itaparica/BA; e, o Casa Grande de Minas ou Casa das Minas Jeje ou Querebentã de Zomadonu, no Maranhão; e o Ilê Obá Ogunté/Sítio Pai Adão, no Recife/PE.

O entendimento da tradição como algo imutável divide opiniões não só dentre do IPHAN, dos espaços religiosos afro-brasileiros, mas também nos debates teóricos. Balandier aborda que a sociedade em seu constante movimento possui desorganizações, rupturas, renovações, então tradição seria esse movimento que permite ao mesmo tempo mudança e permanência.

Provavelmente é a partir dessa visão dialógica de tradição que atuam os espaços religiosos afro-brasileiros, posto que, ao mesmo tempo em que os sacerdotes e as sacerdotisas falam na preservação do culto da forma como realizavam os ancentrais, eles e elas também pensam em como atualizar as tecnologias dentro do terreiro, como adequar as cozinhas de santo as questões sanitárias, entre outras possibilidades de mudança. Portanto, é a partir da tensão entre mudança e permanência que a tradição necessita ser analisada pelo IPHAN e não como algo imutável, fiel as origens do culto em solo africano.

\footnotetext{
${ }^{6}$ Deve ser vista em sua diversidade, posto que, é constituída por vários povos e troncos lingüísticos. Tal olhar deve ser ampliado para as outras nações.
} 
Voltando aos debates de Hall, ao abordar a estética diaspórica, ele apresenta outra possibilidade de discussão dentro das questões da tese, além da postura diante do mundo acadêmico e da questão do mito fundador e da tradição, apresentadas anteriormente. A estética diaspórica é vista por Hall como estética impura, e com isso são muitas vezes observadas a partir da perda, porém, o hibridismo não deve ser visto como padronização das culturas, ao contrário, a estética diáspora mantém seus traços distintivos, inclusive nos

[...]momentos de luta, revisão e reapropriação. Contudo, essa reconfiguração não pode ser representada como uma "volta ao lugar onde estávamos antes". [...] A relação entre as culturas caribenhas e suas diásporas não pode, portanto, ser adequadamente concebida em termos de origem e cópia, de fonte primária e reflexo pálido. (HALL, 2003).

Assim, a partir dos debates trazidos por Hall é possível pensar na estética diaspórica dos terreiros, como uma estética hibrida que se interrelaciona com a estética católica, indígena, e de outros povos, mas ainda assim, se mantém diaspórica a partir dos seus sinais diacríticos. Vale ressaltar que, a diáspora não obedece as fronteiras nacionais, ao contrário ela se entrelaça nas trocas estabelecidas no Atlântico Negro, para Homi Bhabha, a diáspora não tem apenas uma raiz cultural, são várias raízes, portanto, permeada pelo multiculturalismo, a diáspora é transcultural. (BHABHA, 1998).

Hall apresenta a África diaspórica ao leitor,

\begin{abstract}
A África passa bem, obrigado, na diáspora. Mas não é nem a África daqueles territórios agora ignorados pelo cartógrafo pós-colonial, de onde os escravos eram seqüestrados e transportados, nem a África de hoje, que é pelo menos quatro ou cinco "continentes" diferentes embrulhados num só, suas formas de subsistência destruídas, seus povos estruturalmente ajustados a uma pobreza moderna devastadora. A “África” que vai bem nesta parte do mundo é aquilo que a África se tornou no Novo Mundo, no turbilhão violento do sincretismo colonial, reforjada na fornalha do panelão colonial. (HALL, 2003).
\end{abstract}

Reconstruir a identidade do povo negro, do povo de santo a partir da África imaginada, desejada nos tempos da escravização sobrevive dentro dos terreiros. Muitos terreiros têm realizado o caminho de volta com a visita de sacerdotes e sacerdotisas aos locais de culto no continente africano. Essa ligação com a África pode ser lida, também, de outras formas. Como mostra Hall, a África pode ser lida como elemento subversivo, olhar a forma como a África foi "produzida" dentro da narrativa caribenha, e comparar com o universo brasileiro, possibilita ler a África, como elemento subversivo na reconstrução das estruturas na “África em miniatura” ou "Pequenas Áfricas”, nos terreiros, em que os negros em situação de diáspora conseguiram reconstruir e remodelar suas estruturas sociais. 


\section{CONCLUSÃO}

Diante do exposto, das vivências e das discussões travadas durante o componente é possível afirmar que é a partir da consciência histórica que o povo contesta a sua realidade, assim o ato de conhecimento é um ato também político. E nessa perspectiva defender o direito de contar a história a partir do olhar dos sujeitos de pesquisa é um ato político, para Hall os estudos culturais devem ser vistos como uma prática.

Tomando sua idéia emprestada, os direitos culturais também devem ser uma prática, uma intervenção no mundo que faça diferença, não uma teoria, uma letra morte de lei, de Constituição. É necessário defender uma posição, e o aspecto político aponta para as esferas de disputa, e como direciona Hall a teoria nunca deve deixar o pesquisador em paz, porque a pessoa realmente envolvida com os estudos culturais deve sentir e viver a transitoriedade que prática traz.

E se a cultura não é só um conceito, mas também uma forma de poder é preciso pensar em estratégias culturais que façam a diferença e desloquem as disposições de poder, possibilitando, maior acesso aos direitos culturais aos praticantes das religiões minoritárias e patrimonialização dos espaços religiosos afro-brasileiros.

\section{BIBLIOGRAFIA}

AMORIM, Carlos A. [et al.]. Políticas de acautelamento do IPHAN para templos de Culto afro-brasileiros. Salvador: IPHAN, 2012.

BHABHA, Homi K. O local da cultura. Tradução de Myriam Ávila, Eliana Lourenço de Lima Reis e Glaúcia Renate Gonçalves. Belo Horizonte: Editora UFMG, 1998.

BRASIL. Supremo Tribunal Federal (STF). A Constituição e o Supremo. 3 ${ }^{\mathrm{a}}$. ed. Brasília: Secretaria de Documentação, 2010.

FONSECA, Maria C. Londres. Para além da pedra e cal: por uma concepção ampla de patrimônio. In: ABREU, Regina; CHAGAS, Mário (Org.). Memória e patrimônio: ensaios contemporâneos. Rio de Janeiro: DP\&A, 2003.

HALL, Stuart. Da diáspora: identidades e mediações culturais. Organização Liv Sovik, Tradução Adelaine La Guardia Resende[et al]. Belo Horizonte: Editora UFMG, Brasília: Representação da UNESCO no Brasil, 2003. 